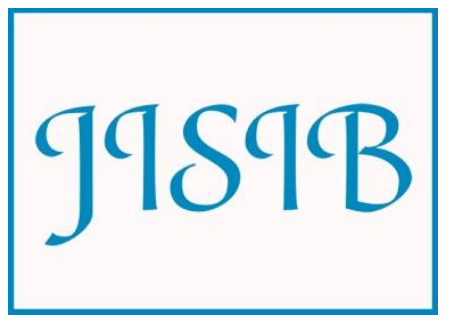

Available for free online at https://ojs.hh.se/

Journal of Intelligence Studies in Business 3 (2013) 54-62

\title{
Big Data, Tacit Knowledge and Organizational Competitiveness
}

\author{
Nowshade Kabir and Elias Carayannis \\ Grenoble Graduate School of Business, France \\ Email:nowshade@gmail.com \\ George Washington University School of Business, USA \\ Email: caraye@gwu.edu
}

Received October 10, accepted 19 December 2013

\begin{abstract}
In the process of conducting everyday business, organizations generate and gather a large number of information about their customers, suppliers, competitors, processes, operations, routines and procedures. They also capture communication data from mobile devices, instruments, tools, machines and transmissions. Much of this data possesses an enormous amount of valuable knowledge, exploitation of which could yield economic benefit. Many organizations are taking advantage of business analytics and intelligence solutions to help them find new insights in their business processes and performance. For companies, however, it is still a nascent area, and many of them understand that there are more knowledge and insights that can be extracted from available big data using creativity, recombination and innovative methods, apply it to new knowledge creation and produce substantial value. This has created a need for finding a suitable approach in the firm's big data related strategy. In this paper, the authors concur that big data is indeed a source of firm's competitive advantage and consider that it is essential to have the right combination of people, tool and data along with management support and data-oriented culture to gain competitiveness from big data. However, the authors also argue that organizations should consider the knowledge hidden in the big data as tacit knowledge and they should take advantage of the cumulative experience garnered by the companies and studies done so far by the scholars in this sphere from knowledge management perspective. Based on this idea, a big data oriented framework of organizational knowledge-based strategy is proposed here.
\end{abstract}

KEYWORDS: Big data, tacit knowledge, big data strategy, knowledge management, knowledge strategies and organizational knowledge 


\section{Opinion Section}

\section{Introduction}

One of the key driving forces of knowledge economy is knowledge intensity of economic activities (Smith, 2002). In recent decades increasing dependence of economy on knowledge has bolstered by rapid pace of technological innovation and information technology revolution. This, in turn, propelled the emergence of new knowledge-based industries and augmented share of knowledge as a resource in economic input in most traditional industries. Knowledge, now, is recognized as a pillar of innovation, a source of economic growth and a central element in organization's competitive advantage (Stehr, 1994). This heightened importance of knowledge, in part thanks to globalization and speedy technological advancement, obliges organizations to pay serious attention to their existing, potential and growing knowledge resources.

Present phenomenal growth of knowledge resource can be attributed to several factors such as continuous advances in information technology related hardware, development of new algorithms and programs, ubiquitous access to information thanks to the Internet and steady decline of cost related to data creation, transmission and storage. In recent years, the combination of these factors has also prompted the appearance of a new knowledge resource, which is capable of further revolutionizing organizational knowledge landscape. This new knowledge resource is big data!

Big data is a unique knowledge resource that is immensely valuable to any organization. It helps transforming many of the traditional methods of conducting business activities. Insights and knowledge from big data boost management's ability to take well-informed decisions (Provost and Fawcett, 2013). Efficient use of data created and located within a firm and collection and analysis of critical data from external sources impact a firm's product, process and strategic innovation as well as marketing and operational capabilities. Current development shows that big data has already become a major catalyst in bringing sweeping changes to a range of business processes in many industries. As a result of this, organizations' interest in big data initiatives has intensified significantly. A study done by Tata consulting (2013) shows that almost half of the companies surveyed have introduced some types of big data projects, and they are expecting a very high return from these initiatives. No doubt that big data is considered as a valuable knowledge resource. If that is the case, what type of knowledge is found in big data? Can this knowledge be considered as tacit knowledge? What should be the right strategy for organizations to handle a knowledge resource as complex as big data? In the article we try to answer to these questions and offer a big data related strategy framework. The rest of the article is divided into several parts: a short discussion on the present interest in big data followed by a review of big data concept, analysis of knowledge and tacit knowledge in the context of big data, a holistic big data strategy model with explanation and finally, the closing remarks.

\section{Why now?}

The emergence of big data phenomenon is the result of a blending of several rising trends: the proliferation of social and business networks, the growth of mobile telecommunication, dramatic cost reduction in data collection, storage, processing and transportation and the increased deployment of sensors and machine to machine communication along with technological advancement in cloud computing, smart ICTs, data mining and analytics (OECD, 2011).

LaValle et al. (2010) assert that companies that use business information and analytical tools in their differentiation strategy have twice as many chances to be in the group of top performers than lower performers of their industry.

Big data can produce minimum two types of values to an organization. Firstly, it can be a source of innovation. Specially, it can enable development of new products, processes and services. Secondly, use of various analytics on big data can generate knowledge and insights that can support and improve organizational decision making significantly (Provost and Fawcett, 2013). The present interest in big data grew mostly thanks to these new value creation possibilities that were unavailable to most companies even recently due to the high cost of data storage, processing and analyzing.

\section{Big Data - the concept}

Big data is a concept that means, firstly, the volume of the data is too large. Secondly, it is impossible to analyze it using conventional technologies, and thirdly, special tools and treatment are necessary to extract knowledge from it (Manyika et al., 2001). Another way of viewing big data is to regard it as a massive pool of data that 


\section{Opinion Section}

allows creating insights and values that are not possible to generate from smaller scale of same data (Jacobs, 2009).

Douglas Laney (2001) of Gartner, while explaining the challenges related to data growth noted that there are three dimensions to this problem: increasing amount of data - the growth of its volume, inflow and outflow speed of data - its velocity and heterogeneity of the data types and sources - data variety, the three Vs. This has become the industry standard in characterizing big data. However, many argues that along with this model, value, veracity and variability also should be included as they are more important than the attributes of 3Vs (Swoyer, 2012).

\section{The concept of knowledge}

Definition of knowledge in organizational science differs from the classical epistemological view of knowledge as "justified true belief" (Nonaka and Von Krogh, 2009). Despite its long history, the concept of knowledge is still subjective, complex and opaque. As a result, we see numerous variations of definitions of knowledge depending on discipline, context, approach and task at hand. In a broader sense, and for the purpose of this article, knowledge can be defined as information that is validated, contextual, relevant and actionable (Soliman and Youssef, 2003). Another similar definition is, knowledge is tested, validated and codified information (Earl, 1994).

Scarbrough \& Barrel (1996) propose the content theory of knowledge, where knowledge is deemed as an object that can be codified and stored. This approach of objectification of knowledge brings flexibility to the perception of knowledge. Knowledge as an object can be acquired, integrated, stored and disseminated much like a commodity and becomes a tradable product (Carlsson et al., 1996). In knowledge science knowledge is also considered as information with meaning, information is data with context and data is a basic element of analysis (Boisot, 1995). This concatenation of data, information and knowledge is the most popular model of their correlation in knowledge and information literature (Rowley, 2007).

\section{Tacit knowledge}

Much of the theoretical understanding of tacit knowledge in knowledge science derives from Polanyi's concept of tacit and explicit knowing (Polanyi, 1962). Tacit and explicit knowledge are two sides of knowledge continuum (Nonaka and Takeuchi, 1995). Explicit knowledge is the type of knowledge, which can be expressed using common language and codes. It is fully transferable and easy to share (Nonaka, 1991). Tacit knowledge, on the other hand, is subjective and informal (Polanyi, 1958; Nonaka, 1995). Taking after Polanyi's view, the concept of tacit knowledge and its place in organizational knowledge creation was largely popularized by Nonaka (1995) and defined as knowledge that indwells human mind and body (Nonaka and Von Krogh, 2009). Many subjectivist scholars believe that tacit knowledge cannot be articulated, captured or interpreted in any form as this type of knowledge gets developed and remains embodied only in the human mind (See Tsoukas 2006). However, others conclude while some tacit knowledge is impossible to explicate, most tacit knowledge can be codified (Nonaka, 1995; Collins, 2010).

We believe that reality exists independently from the human mind and knowledge, including tacit knowledge, can reside in various other silos apart from the human cognizance (Searle, 1993). Many other scholars also support this notion. Walsh and Ungson (1991) posit that knowledge resides in five venues of an organization: people, roles and organizational structures, operating procedures and practices, culture, and the physical structure of the workplace. Hershbach (1995) believes Technological activities embody a larger portion of tacit knowledge than we normally recognize. Some researchers describe tacit knowledge as uncertain, unstructured, indeterminate, and indirect (See Kikoski and Kikoski, 2004) and others conclude tacit knowledge is the kind of knowledge which is implied but not yet documented (Junnarkar and Brown, 1988). These views support the idea that knowledge, insights, patterns, indicators and pointers embedded in big data and waiting to be extracted are a form of tacit knowledge.

\section{Knowledge management strategy}

Organizational knowledge management strategy refers to planning and deployment of methods, processes, procedures and guidelines of knowledge acquisition, organization, utilization and distribution in order to achieve business goals. Knowledge being a valued resource, knowledge management strategy must be always aligned with the organization's business strategy (Eisenhardt and Santos, 2002). For example, focus of knowledge management strategy can be the development of intellectual capital using both knowledge 


\section{Opinion Section}

exploration and knowledge exploitation and as a result gain competitive advantage (Zack, 1999) Knowledge exploitation strategy builds upon existing knowledge and knowledge exploration on acquisition of new knowledge. Both of them are vital in organization's overall knowledge strategy (Ichijo, 2002). These knowledge strategies encompass knowledge processes that include knowledge creation, acquisition, integration, sharing, replication, storage, organization, measurement and identification (Grant, 2008) and require performing balancing act between external and internal factors relevant to organization's goals.

\section{Big data strategy}

The sudden emergence of big data as a source for new knowledge, valuable insights, and innovation and, as a result, competitive advantage has caught many companies off-guard. The fact that management can have a more holistic picture of their business and convert that knowledge to make more informed decision and improve overall company performance is forcing firms to adopt comprehensive big data related knowledge strategies. Mere adoption of a strategy based on industry experience is not good enough. Knowledge strategy, in this case, must be aligned with the expected insights and knowledge received from big data and correlated to the business strategy, so that this new knowledge can be implemented across the board. This means focusing on not just understanding how the insights and knowledge can be infused in the business processes but also take necessary actions to embed the new knowledge in the business processes of most critical areas starting from new product development to customer satisfaction and from manufacturing to logistics.

\section{Big data strategy framework}

Rubenstein-Montano et al. (2001) asserts that a holistic framework of knowledge management that covers general requirements and can be followed by any knowledge management initiative independent of methodologies and tools is essential. Following this suggestion in this paper we propose a universal strategy framework suitable for any organization in relation to big data initiatives from knowledge management strategy perspective. Prerequisites

An organization must possess or develop several critical preconditions in order to implement an initiative successfully, to execute the processes smoothly and to ensure having expected outcome.

\section{Management support}

For any transformation oriented knowledge project to become successful, it requires strong support from management (Davenport et al., 1997). Management support should include: giving clear motivational message to the organization about the importance of the big data project and its benefits in company's success, participating in identifying objectives and domain of the big data projects, allocating finance and other required resources and monitoring success. Success of a big data project depends among others on having a clear understanding of what types of knowledge and insights are necessary in a decision making process. Often, this requires knowledge way beyond data engineering skills of a data specialist. On the other hand, the business decision makers also need to have knowledge about what type of big data can provide needed insights. This means people involved in the big data project either have to have the necessary knowledge and education or they have to develop needed skills and core competencies.

Senior management's commitment and involvement in facilitating learning are crucial in building an adequately knowledgeable team capable of accomplishing big data project related assignments.

\section{Infrastructure}

Organizational Infrastructure includes people, process, technology, structure and their correlation. Big data related infrastructure needs to be focused on innovation and knowledge creation and, as a result, should have a high degree of flexibility and freedom. To achieve set strategic objectives organizational structure and roles should ensure a seamless flow of best practices throughout the firm. Strategic goals setting and decision making in relation to the big data project should come from top management. If the big data initiative envisioned to be a large project, it makes sense to appoint a chief data officer who can oversee all data related projects.

\section{People}

Big data projects need to have different skills set than organizations are normally accustomed to. This is one of the added reasons why it is necessary to pay special attention to the key success factor of a big data project - people. Depending on the kind of technologies the company is planning to implement, 


\section{Opinion Section}

it would require at the IT level specialists in cloud architecture, Hadoop, MapReduce, Semantic Webs and number of other key areas. Vital to big data project are the holders of a new job title called data scientist. Data scientists are necessary for making sense from big data. Business intelligence professional understands the business decisions needs and capable of analyzing the big data in order to divulge correlations, knowledge and insights.

BIG DATA STRATEGY FRAMEWORK

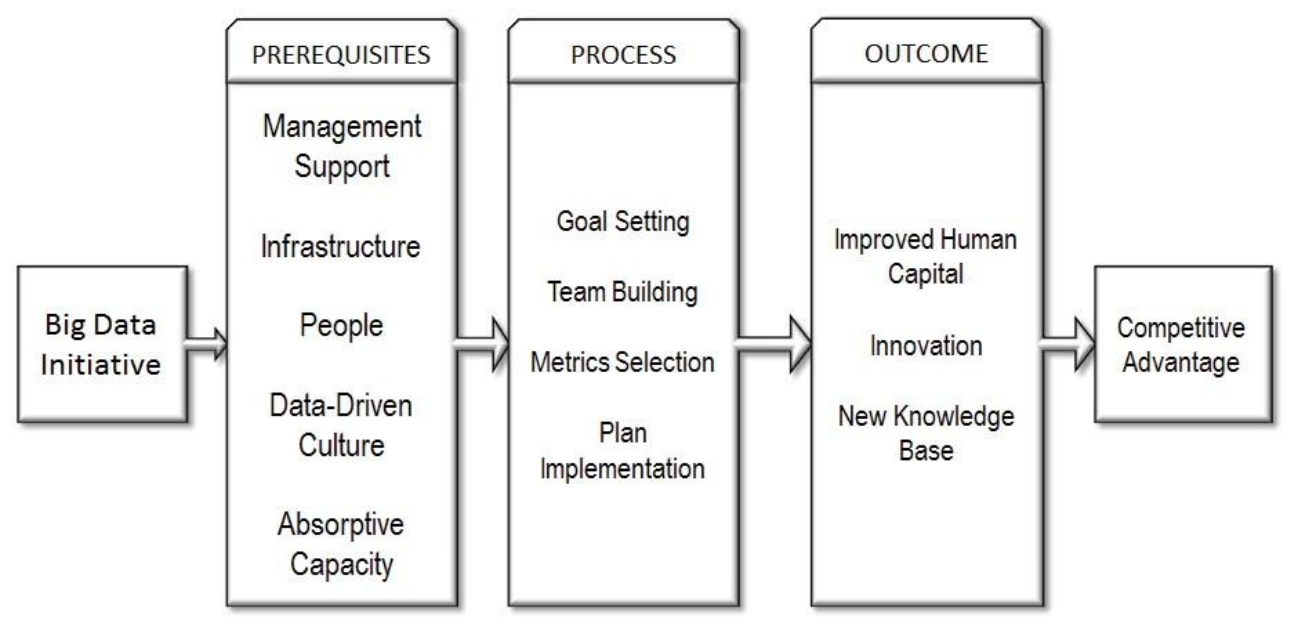

Figure 1: Big data strategy framework

\section{Data-driven culture}

Organizational culture is the collective programming that includes vision, norms, values, symbols, rituals, beliefs, habits and attitudes of the members that work as a normative glue in unifying the organization and influence the behavior of an individual member (Hofstede, 1996).Having a data-driven culture that fosters implementation of big data projects is imperative for a firm that is striving to have competitive edge using data-based decision-making and business analytics. Datadriven culture means having a clear understanding among the employees that data is everybody's business not just IT departments and data has to be taken in consideration in almost all decision making. A study by Economist Intelligence Unit shows that there is a strong positive link between data-driven decision-making and organizational performance. Moreover, data driven companies with superior performance regard data sharing as a valuable process. They also consider that shared data needed to be used across the board and all units should collect data proactively (The Economist, 2013).

\section{Absorptive capacity}

The concept of "Absorptive Capacity" is defined as "ability of a firm to identify, assimilate and exploit knowledge from the environment" (Cohen and Levinthal, 1989: p. 569). Absorptive capacity is considered as part of dynamic capabilities of the firm and are divided as potential absorptive capacity, which derives from knowledge acquisition and integration abilities and realized absorptive capacity, which encompasses transformation and exploitation of knowledge (Zahra and George, 2002). Absorptive capacity is the firm's capability of developing skills related to tacit knowledge (Mowery and Oxley, 1995). Kim (1997) deems that it is the firm's learning and problem solving ability and Kedia and Bhagat (1988) view that absorptive capacity is firm's ability to transform in accordance with technological shift.

\section{Processes}

A key reason for paying attention to processes in strategy is the need for the organization to grasp how technologies, people, and processes in combination influence its business performance.

\section{Goal setting}

The first and foremost goal for a company that is seriously investing in big data should be to depict a clear vision that emphasizes on the expected strategic outcome from the realization of the big data projects. In setting goals and developing roadmaps, all relevant departments and units need to participate. Setting achievable and measurable goals is vital for the success of a big data project as half 
of the big data projects initiated never get completed (LaValle et al., 2011).

\section{Team building}

Because of the complex knowledge and skill set that are required for receiving effective results from a big data project, it is necessary to organize the team according to organization's business objectives. The two most needed members of such a team are a data scientist and a business analytics professional. Other members may include IT specialists and workers from the business department most relevant to the data project. For example, if the big data team is working on finding a solution related to marketing, for best result it has to incorporate people from the marketing department as well (Ohlhorst, 2013). Mistake will be to assign the team to IT department. Analyzing information from a number of large corporations, researchers found that while IT departments are highly efficient in data storage and protection, they are unable to offer solutions that can convert data into business value (Beath et al., 2012). More over, organizations that are endowed with a large amount of big data, they have 70 percent more chances of having business intelligence projects initiated by the business community rather than IT people (Rowe and White, 2012).

\section{Technology selection}

Big data projects are complex systems requiring various types of information technologies that encompasses from storage to applications and include data warehouse solutions, information and data management, virtualization and visualization, different analytical tools to name a few. These elements can be divided into three categories: Warehouse infrastructure, big data analytics platforms and big data applications. Big data analytics is not a recent phenomenon. Business intelligence tools are getting used in business decision making for more than several decades. What is new now is the explosive growth of data and capacity to store that data. The sudden popularity of big data can be attributed to the new technological platforms that haveemerged recently. They are capable of processing and analyzing data in various structures outperforming traditional database technologies in massive scale. Selection of needed technologies will depend on the followings: data amount, speed of data flow, structure of data expected to be used, integration requirement of the data, expected outcomes from the data analysis, users' need, costs, etc.

\section{Metrics selection}

The criticism of financial performance based management style that does not accommodate knowledge as one of the most valuable assets has been well documented (Meyer and Gupta, 1994). Efforts have been made to develop performance measurement frameworks that are more encompassing and comprehensive in relation to intangible assets (Epstein and Manzoni, 1997) and which in various degrees encapsulate knowledge assets measurements (See for example: Edvinsson and Malone, 1997). Since, big data analytics don't impact on the revenue generation directly, the ROI analysis metrics should include indirect benefits that emanate from the big data initiative.

\section{Plan implementation}

In line with the strategic goals and expected outcome, a firm needs to create and deploy a roadmap of big data initiative. Along with setting objectives and milestones, selecting teams members and developing proof of concept one more important issue is to identify and obviate stifles related to the specificity of big data initiative environment. Big data fundamentally differ from any other technology related projects. At one side, the team members work with the high velocity, high volume, high intensity and complex data in a real-time environment of discovery and innovation, but the insights and knowledge garnered in this environment ultimately need to be aligned with traditional technology based environment of data compliance, governance, security and perfunctory decision making. Organizations should be aware that this coupling of the two different environments might not go smoothly and may have a negative impact on the implementation of a well developed plan.

\section{Outcome}

The big data generated by the organization's business processes and operational activities, which include innovation and knowledge related activities, as well as employee's skill development, have all the potential to become instrumental to developing competitive advantage. The big data base innovations are still in its infancy! Early signs from various large corporations, however, demonstrate the immense possibilities that are hold in the tacit knowledge hidden in big data.

\section{Improved human capital}

One of the fundamental elements of organizational intellectual capital is human capital (Edvinsson and 
Sullivan, 1996). Stewart (1999) defines intellectual capital as a combination of intellectual elements that include knowledge, information, intellectual properties and experience that are applied to generate wealth. The execution of big data projects requires hiring new talents and developing new professional skills among existing workers. The experiences of the professionals developed in the process of big data project are indubitably valuable assets. Their contribution to the creation of new knowledge and innovative products, services and processes has a positive influence on the top and bottom lines of an organization.

\section{Innovation}

Most organizations understand that key to sustainable competitive advantage in today's globalized and wired world is innovation. In fact, Innovation capabilities, arguably, are the most important determinant of firm's performance (Mone et. al., 1998). Big data is an enabler, a driver and a source of new products, processes, services, strategies and business models (Manyika et al., 2011). Through big data capturing, aggregating, storing and analyzing companies from every industry and sector have the potential to reap benefits of innovation. Innovations originated and spawned from big data can be divided into three categories:

Big data-driven innovation: Innovation where big data is the primary material in the development of a product, service, process or model. One example is high speed trading.

Big data enabled innovation: In an innovation where big data works as a catalyst. Examples are: Determining marketing campaign effectiveness, using sensors data to predict machinery failure, monitoring customer's experience of a product and finding design and manufacturing problems.

Big data related innovation: Technology, process and service innovation that opens new possibilities in handling big data. Example could be a new inhouse business analytics technique.

\section{New knowledge base}

Knowledge acquired from diverse sources is crucial for creating new knowledge. Organizations pursue externally sourced knowledge actively as the more knowledge absorbed from external sources the better the chances of new types of knowledge recombination and generation (Cohen and Levinthal, 1989). Developing dynamic capabilities that help recognizing new possibilities and capturing new business opportunities thanks to aggressive acquisition of external knowledge, which in turn leads to better innovation, is a key to firm's competitiveness (Zhou and Uhlaner, 2009). Big data initiative develops a kind of dynamic capability that contributes significantly to organizations knowledge base in respect to knowledge repositories, employees' knowledge foundation and absorptive capacity.

\section{Conclusion}

In this paper, we have explored the idea that knowledge residing in the big data is indeed tacit and in most of the cases open to explicability. Once extracted this new knowledge can be transferred, used and shared much like any other explicit knowledge. This new and unique knowledge has all the potential of creating economic value for an organization and bolster innovation, productivity and growth. Thus, It is also a possible major source of competitive advantage.

We then proposed a big data centric knowledge strategy framework that outlines requirements, processes and outcomes of a big data initiative that aims at creating competitive advantage. We recommend consulting and adopting the strategy framework prior to engaging in a big data project. The main limitation of this paper is, although, in this paper we have delineated a strategy model that can be implemented in any organization, the concept is not validated by any empirical research. We suppose that study covering multiple industries on the impact of this strategic framework is necessary to identify its strength and weakness.

\section{References}

Beath, C., Becerra-Fernandez, I., Ross, J. and Short J. (2012). The Forrester Wave: Advanced Data visualization Platforms, Q3

Boisot, M. (1995). The Information Space. Routledge, London.

Carlsson, S. (2003). Knowledge managing and knowledge management systems in interorganizational networks. Knowledge and process management, 10(3), pp. 194-206.

Cohen, W. and Levinthal, D. (1989). Innovation and learning: The two faces of R\&D, The Economic Journal, Volume 99, September, pp. 569-596.

Collins, H. (2010). Tacit and explicit knowledge. University of Chicago Press.

Davenport, T.H., De Long, D.W. and Beers, M.C. (1997) Building Successful Knowledge Management Projects. 
Earl, M. J. (1994) The new and the old of Business Process Redesign, Journal of Strategic Information Systems, 3(1), March, pp. 5-22.

Edvinsson, L., Sullivan, P. H. (1996). Developing a model for managing intellectual capital. European Management Journal, 14(4), pp. 356364

Epstein, M. \& Manzoni, J-F. (1997). The balanced scorecard and tableau de bord: translating strategy into action. Management Accounting (US) august pp. 28-36.

Galunic, D.C. and Rodan, S. (1998). Resource Recombination in the Firm: Knowledge Structures and the Potential for Schumpeterian Innovation. Strategic Management Journal, 19: pp. 1193-1201.

Hofstede, G. (1996). Cultures and Organizations, Software of the Mind: Intercultural Cooperation and its Importance for Survival, McGraw-Hill

Jacobs, A. (2009). The pathologies of big data. Communications of the ACM,52(8), pp. 36-44.

Jones, P., Packham, G. and Miller, C. (2007) Do You Mean Us: the experience of teaching enterprise education in Germany? 21st British Academy of Management conference, 11-13th September, Paper ref: BAM-10429, ISBN: 0-9549608-3-1.

Junnarkar, B. and C. Brown (1997) Re-assessing the enabling role of information technology in KM. Journal of Knowledge Management 1(2): pp.142148.

Kedia, B.L., and Bhagat, R.S. (1988). Cultural constraints on transfer of technology across nations: Implications for research in international and comparative management, Academy of Management Review, 13:4, pp. 459-571.

Kikoski, K. C. and Kikoski, F. J. (2004). The Inquiring Organization: Tacit Knowledge, knowledge and organizational knowing Organization Science, 10(4), pp.381-400.

Kim, L. (1998). Crisis construction and organizational learning: Capability building in catching-up at Hyundai Motor. Organization Science, 9(4), pp. 506-521.

Laney, D. (2001), 3-D Data Management: Controlling Data Volume, Velocity and Variety, META Group Research Note, [online] http://goo.gl/Bo3GS.

LaValle, S., Lesser, E., Shockley, R., Hopkins, M. S., $\&$ Kruschwitz, N. (2011). Big data, analytics and the path from insights to value. MIT Sloan Management Review, 52(2), pp. 21-31.

Manyika, J., Chui, M., Brown, B., Bughin, J., Dobbs, R., Roxburgh, C., \& Byers, A. H. (2011). Big data: The next frontier for innovation, competition, and productivity.
Meyer, M.W. and Gupta, V. (1994), "The performance paradox", Research in Organizational Behavior, Vol. 16, pp. 309-69.

Mone, M.A., McKinley, W. and Barker, V.L. (1998) Organizational decline and innovation: a contingency framework The Academy of Management Review, Jan 1998, Volume: 23 Issue: 1 pp.115-132.

Mowery, D. C., \& Oxley, J. E. (1995). Inward technology transfer and competitiveness: the role of national innovation systems, Cambridge Journal of Economics, 1995 - CPES.

Murphy, C. (2003). Tying it all together, Information Week, March 17, 8700225.

Nonaka, I. \& Takeuchi, H. (1995). The knowledgecreating company. Oxford University Press, NY.

Nonaka, I. (1991). The Knowledge Creating Company. Harvard Business Review 69:6: pp. 96104.

Nonaka, I. (1995) The Knowledge-Creating Company, Oxford Press, NY.

Nonaka, I., \& Von Krogh, G. (2009). PerspectiveTacit knowledge and knowledge conversion: Controversy and advancement in organizational knowledge creation theory. Organization science, 20(3), pp. 635-652.

OECD (2013). Exploring Data-Driven Innovation as a New Source of Growth: Mapping the Policy Issues Raised by "Big Data", OECD Digital Economy Papers, No. 222, OECD Publishing.

Ohlhorst, F. (2013). Big Data Analytics - Turning Big Data into Big Money, John Wiley \& Sons, Inc., New Jersey.

Polanyi, M. (1958 \& 1962). Personal Knowledge: Toward a Post-critical Philosophy, University of Chicago Press, Chicago, IL.

Provost, F., \& Fawcett, T. (2013). Data Science and its Relationship to Big Data and Data-Driven Decision Making. Big Data, 1(1), pp. 51-59.

Rao, M. (2012). Knowledge Management Tools and Techniques In Knowledge Management Tools and Techniques, pp. 3-4. Abingdon, Oxon: Routledge.

Rowe, N. and White, D. (2012). Go Big or Go Home? Maximizing the Value of Analytics and Big Data, Aberdeen Group.

Rowley, J. (2007). The wisdom hierarchy: Representations of the DIKW hierarchy. Journal of Information Science 33: pp. 163-180.

Rubenstein-Montano, B. et al. (2001). A systems thinking framework for knowledge management. Decision Support Systems 31 (1): 5, pp. 5-16

Scarborough, H. \& Burrell, G. (1996). The Axeman Cometh: The Changing Roles \& Knowledge of Middle Managers in S. Clegg \& G. Palmer (eds): 
The Politics of Management Knowledge, London: Sage.

Smith, K. H. (2002). What is the 'Knowledge Economy'? Knowledge intensity and distributed knowledge bases (Doctoral dissertation, United Nations Univeristy, Institute for New Technologies).

Soliman, F. and Youssef, M. (2003). The role of critical information in enterprise knowledge management, Industrial Management \& Data Systems, Vol 103, No.7, pp. 484-90.

Stehr, N. (1994). Knowledge societies. Blackwell Publishing Ltd.

Stewart, T. (1999). Intellectual Capital: The New Wealth of Organizations 1st ed., New York, New York: Doubleday. Swoyer, S. (2012). Big Data Why the 3Vs Just Don't Make Sense, Agile White Paper, [online] http://www.myagiledata.com/articles/share/1875 9/, accessed on September 01, 2013.

Tata Consulting Services (2013). The Emerging Big Returns on Big Data - a TCS 2013 Global Trend Study, India.
Teece, D.J., Pisano, G., Shuen, A. (1997). Dynamic Capabilities and Strategic Management, Strategic Management Journal, Vol. 18:7, pp. 509-533.

The Economist, (2013). Fostering a Data-Driven Culture, Economist Intelligence Unit.

Tsoukas, H. (2006). Complex Knowledge: Studies in Organizational Epistemology, Organization Studies October 2006 27, pp. 1563-1569.

Van den Bosch, F. A. J., A. P. de Man, eds. (1997). Perspectives on Strategy. Kluwer Academic Publishers, Boston.

Walsh, J.P. and Ungson, G.R. (1991). Organizational memory, Academy of Management Review, Vol. 16, pp. 57-91.

Zack, M. H. (1999). Managing codified knowledge. Sloan management review,40 (4), pp. 45-58.

Zahra, S. and George, G. (2002). Absorptive Capacity: A Review, Reconceptualization and Extension", Academy of Management Review, Volume 27, Issue 2, pp. 185-203.

Zhou, H., \& Uhlaner, L.M. (2009). Knowledge management as a strategic tool to foster innovativeness in SMEs. (ERIM report series ERS-2009-025-ORG) Rotterdam: Erasmus Research Institute of Management. 